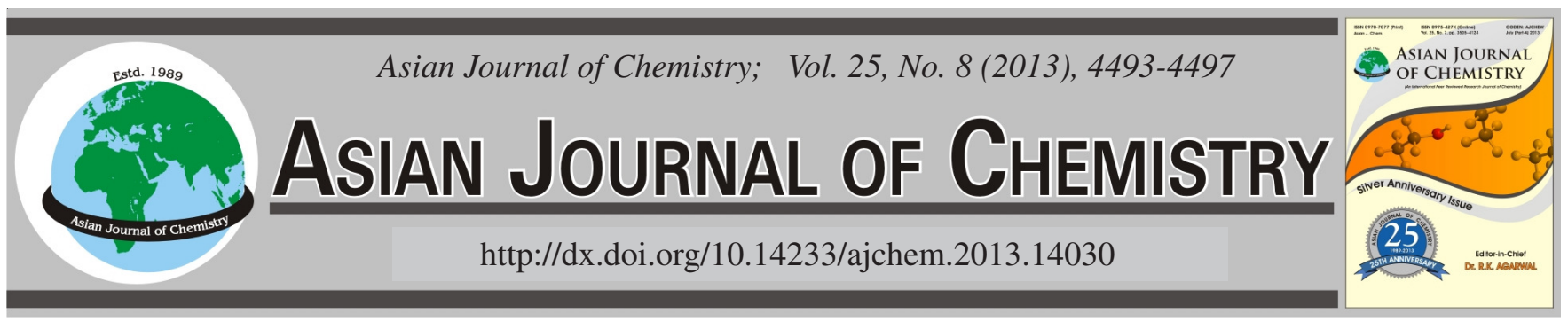

\title{
Clean Synthesis of Pharmaceutical Intermediate 2,2'-Dithiobis(benzothiazole) in Fluidized Bed Reactor
}

\author{
Chunguang Chen $^{1,2, *}$, Weiwei Niu ${ }^{3}$, Yaqing Feng $^{1}$ and Xuexi $\mathrm{Chen}^{4}$
}

${ }^{1}$ School of Chemical Engineering And Technology, Tianjin University, Tianjin, P.R. China

${ }^{2}$ Huangdao Import and Export Inspection and Quarantine Bureau, Qingdao, P.R. China

${ }^{3}$ School of Polymer Science and Engineering, Qingdao University of Science \& Technology, Qingdao, P.R. China

${ }^{4}$ School of Chemical Engineering And Technology, Qingdao University of Science and Technology, Qingdao, P.R. China

*Corresponding author: E-mail: chen_chun_guang@hotmail.com

Refined 2-mercaptobenzothiazole was produced by recrystallization from 2-mercaptobenzothiazole with industrial grade and oxidized to 2,2'-dithiobis(benzothiazole), using oxygen as an oxidant, nitric oxide as a oxygen carrier and alcohols as solvents, in a circulating fluidized reactor under one-step oxidation. 2,2'-Dithiobis(benzothiazole) was thus obtained with high purity up to $99 \%$, melting point at $183{ }^{\circ} \mathrm{C}$, high yield over $98 \%$, through the optimization of reaction parameters as reaction time, temperature, reactants ratio, with less waste generation and emission during the production process. Alcohol solvents can be reused after purification.

Key Words: Pharmaceutical intermediate, 2,2'-Dithiobis(benzothiazole), Circulating fluidized bed reactor.

\section{INTRODUCTION}

2,2'-Dithiobis(benzothiazole) (DM) is an excellent accelerant for rubber vulcanization. It is widely used in rubber industry meanwhile it is a pharmaceutical intermediate with high activity. In recent years, DM was used to synthesize benzothiazole ester which is a precursor drug for cephalosporin antibiotics ${ }^{1-3}$. The melting point of industrial grade DM used in rubber industry is required to reach $170{ }^{\circ} \mathrm{C}$. However, the DM used in pharmaceutical industry requires its melting point above $180^{\circ} \mathrm{C}$, with fewer impurities, high activity, facilitating organic synthesis and quality control in pharmaceutical industry.

2,2'-Dithiobis(benzothiazole) produced from $\mathrm{M}$ is generally oxidized in aqueous solutions with various oxidants, such as air, chlorine, sodium hypochlorite, potassium bromate, ozone, hydrogen peroxide etc. ${ }^{4-12}$. The purities of DM are different due to their different oxidation capacity. However, their melting points are all under $175^{\circ} \mathrm{C}$ and thus do not meet the requirements (high melting point, short melting range, few impurities and good quality) of the pharmaceutical industry. Many researchers have concentrated their work on this improvement. Nolte et al. ${ }^{13}$ used DMBA as the solvent, $\mathrm{O}_{2}$ as an oxidant, the product purity and yield were all above 99 $\%$, but the melting point was relatively low. Shah et al. ${ }^{14}$ used $\mathrm{O}_{2}$ as an oxidant, acetonitrile as solvent to prepare high purity DM with the presence of CsF-Celite. However, due to the preciousness of CsF-celite and toxicity of acetonitrile, this method is not appropriate for practical production. To meet the demand of pharmaceutical industry, Zhai ${ }^{15}$ has introduced a method, using toluene as solvent to dissolve industrial grade $\mathrm{DM}$ and then obtain refined product by recrystallization. The melting point of the refined $\mathrm{DM}$ can reach $181^{\circ} \mathrm{C}$ and basically meet the requirements of the production of active esters. However, after secondary crystallization, the activity of the crystal becomes lower in the subsequent synthetic process and the reaction time was prolonged. Furthermore, using flammable toluene has the potential to cause danger during the production and make harms to the health of onsite operators.

Hydrogen peroxide can be used as an oxidant, under the presence of water/ROH mixed solvents ( $\mathrm{R}=$ isopropyl, cyclohexyl), by one-step oxidation, convert $\mathrm{M}$ directly into DM with high purity sufficient for pharmaceutical uses. Since that there was no emission of waste gas and that alcohols solvents were non-toxic and could be reclaimed, the environment around the whole process had been improved. However, hydrogen peroxide has a strong oxidation capacity, prone to produce a small amount of by-products, such as sulfinic acid, sulfenic acid and sulfonic acid. Furthermore, the melting point of the product is still below $180^{\circ} \mathrm{C}$, even under the optimized processing.

In this paper, we propose oxygen as an oxidant, nitric oxide gas as the catalyst ${ }^{16}$, in a circulating fluidized bed in 
order to obtain DM with high purity for pharmaceutical uses. The oxidation potential of oxygen is relatively low, e.g., its standard electric potential is around $1 \mathrm{~V}$ and thus side reactions are avoided. Oxygen is used instead of air,due to the fact that nitrogen gas (in air) can carry nitric oxide (generated by sulfuric acid-sodium nitrite reaction) out of the reaction system, which result in serious atmosphere pollution. For the high purity of the product, refined 2-mercaptobenzothiazole was obtained from 2-mercaptobenzothiazole with industrial grade by recrystallization using a novel solvent system, water/ROH. This process is efficient, nontoxic, without emission of waste water and gases.

\section{EXPERIMENTAL}

\section{Mechanism and method}

Reaction mechanism: $M$ contains a thiol functional group. S atom has an empty $d$-orbit and the sulfur-hydrogen bond is easy to break. Therefore, thiol is much easier to be oxidized than alcohols. The oxidation occurred on $\mathrm{S}$ atom ${ }^{1}$.

Weak oxidant can oxidize thiol to disulfide chemical compound. For example, oxygen in air can oxidize M to DM.

$$
2 \mathrm{RSH}+1 / 2 \mathrm{O}_{2} \longrightarrow \mathrm{RSSH}+\mathrm{H}_{2} \mathrm{O}
$$

The oxidation of $\mathrm{M}$ carried out as free radical reactions.

$$
\begin{aligned}
\mathrm{RSH}+[\mathrm{O}=\mathrm{O} \rightarrow \cdot \mathrm{O}-\mathrm{O} \cdot] & \rightarrow \mathrm{RS} \cdot+\mathrm{HOO} \cdot \\
& +\mathrm{RSH} \rightarrow \mathrm{RS} \cdot+\mathrm{HOOH} \\
2 \mathrm{RS} \cdot \rightarrow \mathrm{RSSR} &
\end{aligned}
$$

Usually the free radical reaction cannot reach to the end completely. If the reaction process cannot be efficiently controlled, it will lead to the impurity of the products and affect the quality of the subsequent products.

\section{Method}

Refining of M: M was heated and dissolved in water/ $\mathrm{ROH}$, using micro-membrane to filter off the brown polybenzothiazole colloid and got a clear solution. Then cooled down the solution, crystallized and collected the crystal. After washing and drying the collected crystal, the refined $\mathrm{M}$ was obtained. Distilled the solvent after $\mathrm{M}$ was separated, remove the impurities then the solvents can be reused.

Preparation of DM: Refined M was added into the circulating fluidized bed reaction system (Fig. 1). Connected vacuum pump, draw out air from the system to ensure a certain vacuum degree. Added a certain amount of water/ROH into the system, started the hot water circulating pump that connected to constant temperature water-bath, heated the system to a preset temperature and started a liquid circulating pump. Switched on the pressure relief valve of the steel cylinders, a certain amount of oxygen and nitric oxide gas was passed into the system. The solvent carried $\mathrm{M}$ solid and kept making vapour-liquid contact with mixed gases $\left(\mathrm{O}_{2}\right.$ and $\left.\mathrm{NO}\right)$ sufficiently, so the oxidizing reaction can be completed in a short time. Used cloud point titration to examine remaining $M$ in liquid phase meanwhile observed the colour changing of the liquid, separated the product in time, filtered and collected the solid, after washing and drying, DM product was obtained. HPLC method was set up to measure the product purity ${ }^{17}$. Triethyl phosphate was used to dissolve the product and detect the insoluble substance inside.

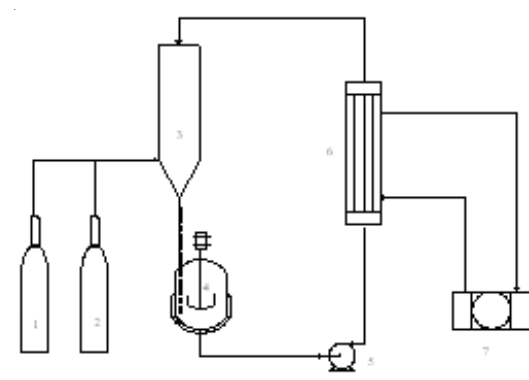
1. $\mathrm{O}_{2}$ cylinder
2. NO cylinder
3. Gas-liquid contactor
4. Stirred tank reactor
5. Circulating pump
6. Heat exchanger
7. Thermostat water bath and pump

Fig. 1. Circulating fluidized bed system for DM preparation

\section{RESULTS AND DISCUSSION}

Comparison of refining methods for industrial grade M: When using aniline as starting material, the byproduct of manufacturing $\mathrm{M}$ is benzothiazole. It can easily be polymerized to brown colloid. The crude M contains $\mathrm{ca}$. $15 \%$ polybenzothiazole. After dissolving in alkali and being neutralized with acid there are still parts of polybenzothiazole colloid left, which will mix with DM continuously. During the synthesis of some cephalosporins, DM can be used as protective group. The quality of DM should be strictly controlled to ensure the quality of these antibiotics. The clarification test is aimed to test the existence of polybenzothiazole, in which polybenzothiazole cannot be dissolved in diethyl phosphate, shown as filamentous colloid.

In a traditional method, 2-mercaptobenzothiazole was refined with alkali-acid method. Sodium hydroxide and other alkalis were used to dissolve $\mathrm{M}$ in order to filter off most of the polybenzothiazole colloid. Then sulfuric acid and other acidic substances were used to neutralize it into pure M. As the particle sizes of polybenzothiazole molecules are widespread, some small colloid particles cannot be removed completely under this refining process. In fact, the level of insoluble substances in DM product can nont meet the requirement even if after secondary alkali-acid refining.

Our research used organic conception diagrams to select water/ROH and adopted this solvent to dissolve, crystallize and refine industrial $\mathrm{M}$. As $\mathrm{M}$ is dissolved in mixed solvent water/ROH, with temperature changes (Table-1).

\begin{tabular}{cc|cc}
\multicolumn{5}{c}{ TABLE-1 } \\
\multicolumn{4}{c}{$\begin{array}{c}\text { EFFECT OF TEMPERATURE ON THE SOLUBILITY } \\
\text { OF M IN WATER/ROH MIXED SOLVENT }\end{array}$} \\
\hline $\begin{array}{c}\text { Temperature }(\mathrm{t}) \\
\left({ }^{\circ} \mathrm{C}\right)\end{array}$ & $\begin{array}{c}\text { Solubility } \\
(\mathrm{w} / \mathrm{wt} \%)\end{array}$ & $\begin{array}{c}\text { Temperature }(\mathrm{t}) \\
\left({ }^{\circ} \mathrm{C}\right)\end{array}$ & $\begin{array}{c}\text { Solubility } \\
(\mathrm{w} / \mathrm{wt} \%)\end{array}$ \\
\hline-10 & 47.8 & 30 & 58.2 \\
0 & 49.1 & 40 & 61.1 \\
10 & 51.0 & 50 & 64.2 \\
20 & 54.7 & - & - \\
\hline
\end{tabular}

It can be concluded from Table-1 that 2-mercaptobenzothiazole has a high solubility in water/ROH and with the rising of the temperature, the solubility changes apparently. We first dissolved $\mathrm{M}$ in water/ROH under the temperature of 50-60 ${ }^{\circ} \mathrm{C}$, used ceramic membrane for filtration while hot. In the filter cake that hampered by the membrane, there existed a brown transparent filter layer which was composed of polybenzothiazole with high degree of polymerization. However, the polybenzothiazole with low polymerization degree can be 
dissolved in the solvent and left in the filtrate. When cool to room temperature, 2-mercaptobenzothiazole is crystallized, isolated and washed, regular crystals can be obtained, the melting point of this refined $\mathrm{M}$ is $182-183{ }^{\circ} \mathrm{C}$. ${ }^{1} \mathrm{H}$ NMR (DMSO- $\left.d_{6}, 500 \mathrm{MHz}\right): \delta 7.24-7.31(2 \mathrm{H}, \mathrm{m}, \mathrm{CH}), 7.37(1 \mathrm{H}, \mathrm{d}$, $\mathrm{CH}), 7.66(1 \mathrm{H}, \mathrm{d}, \mathrm{CH}), 13.8(1 \mathrm{H}$, brs, $\mathrm{SH})$. The purity of the refined $\mathrm{M}$ can above $99.7 \%$. (HPLC and ${ }^{1} \mathrm{H}$ NMR spectrums are shown in supplementary material).

Effect of reaction temperature on the oxidation of $M$ : Under the condition of adding raw materials time $1 \mathrm{~h}$, reaction time $2 \mathrm{~h}, \mathrm{M}$ : solvent $=1: 5, \mathrm{O}_{2}: \mathrm{NO}=20: 1$. Inspected the reaction temperature influence on initial melting point and melting range (Fig. 2).

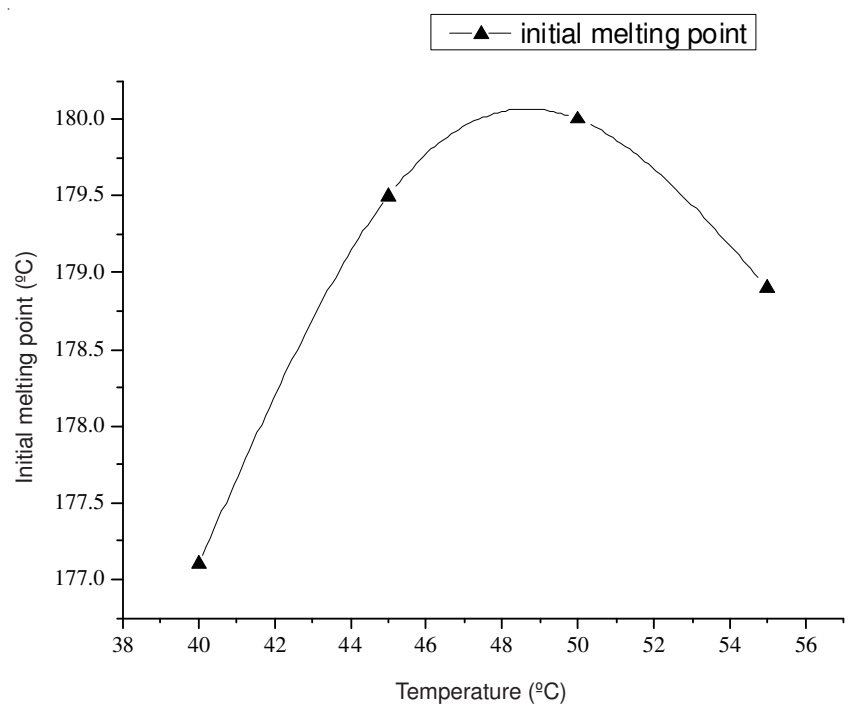

Fig. 2. (a) Temperature influence on initial melting point of $M$

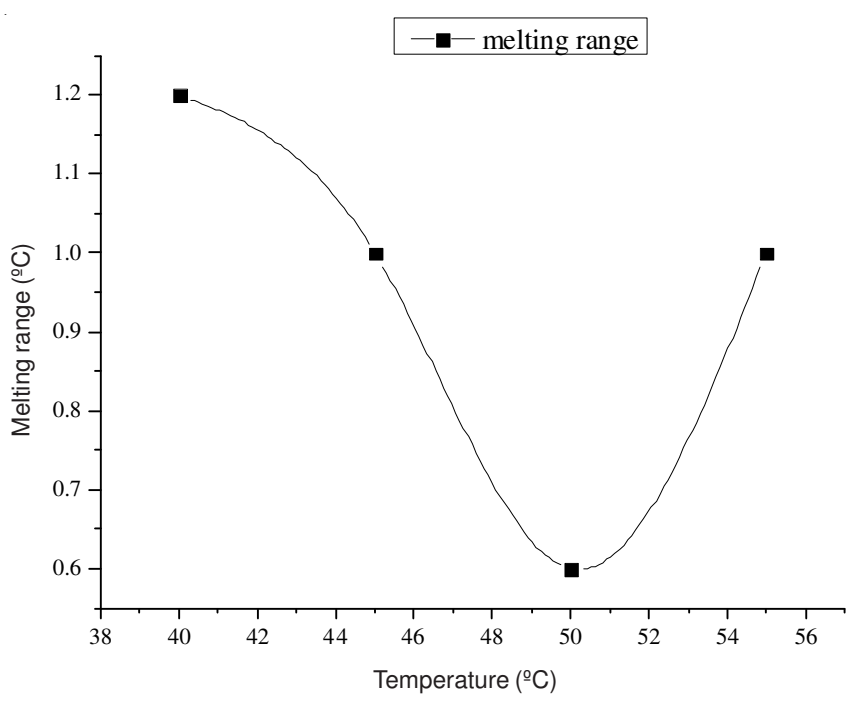

Fig. 2. (b) Temperature influence on melting range of $M$

It can be seen from Fig. 4 with the rising of reaction temperature, the initial melting point first increased and then decreased and the melting range first narrowed then enlarged. The products of high quality should have high melting points and narrow melting range. So the suitable reaction temperature is $50{ }^{\circ} \mathrm{C}$.
Effect of oxygen partial pressure on the oxidizing speed of $\mathbf{M}$ : The oxidation of $\mathbf{M}$ is a free-radical reaction that has an induction period ca. 5-10 min. During the induction period, the oxidation of $\mathrm{M}$ can hardly occurs. Once it is triggered, the reaction can be accelerated. The reaction speed depends on the oxidant supplying speed.

The experiment needed to evacuate the fluidization reactor system partly, filled with $\mathrm{O}_{2}$ and $\mathrm{NO}$ gas, kept the system at atmospheric pressure. Under the following reaction conditions: temperature $50{ }^{\circ} \mathrm{C}, \mathrm{M}$ : solvent $=1: 5, \mathrm{O}_{2}: \mathrm{NO}=$ 30:1, observed the influence of oxygen partial pressure on M's complete oxidizing time. As shown in Fig. 5, the test method whether $\mathrm{M}$ is complete oxidized or not is to take out some reaction solution and dilutes it with water. After dilution if the liquid is clear that indicates $\mathrm{M}$ has been completely oxidized to DM.

Fig. 3 shows the relationship between oxygen partial pressure and reaction time. With the increase of oxygen partial pressure, the oxidation time significantly shortens. Meanwhile, as the reaction speeds up, the temperature rises, the particle sizes of DM crystal become smaller. When the oxygen partial pressure reaches $60 \mathrm{KPa}$, the melting point of DM decreased rapidly. To ensure the quality of DM the oxygen partial pressure should be no more than $50 \mathrm{KPa}$.

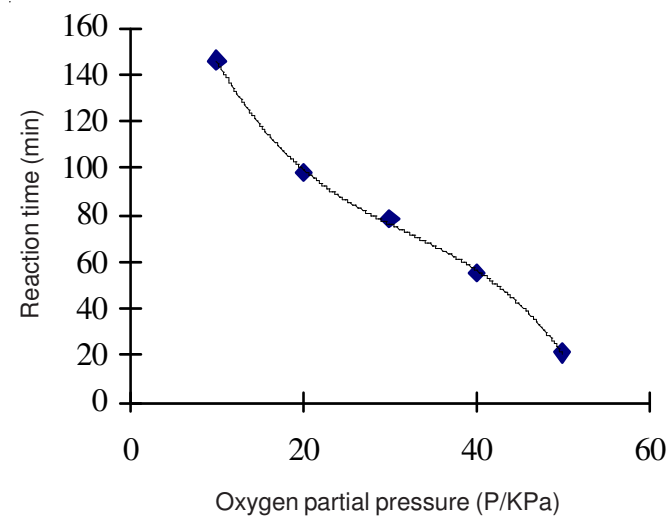

Fig. 3. Relationship between oxygen partial pressure and reaction time

Effect of nitrogen oxide quantity on the M oxidation: With the absence of nitrogen oxide gas, the oxidizing speed of $\mathrm{M}$ in $\mathrm{O}_{2}$ was very slow. With the participation of $\mathrm{NO}$, the oxidizing reaction of $\mathrm{M}$ was as follows:

$$
2 \mathrm{NO}+\mathrm{O}_{2}=2 \mathrm{NO}_{2}
$$

$\mathrm{NO}_{2}$ is easily dissolved in water.

$$
\mathrm{NO}_{2}+\mathrm{H}_{2} \mathrm{O}=2 \mathrm{HNO}_{3}+\mathrm{NO}
$$

Diluted $\mathrm{HNO}_{3}$ is oxidative; it can oxidize $\mathrm{M}$ to $\mathrm{DM}$

$$
2 \mathrm{HNO}_{3}+4 \mathrm{RSH}=2 \mathrm{RSSR}+3 \mathrm{H}_{2} \mathrm{O}+\mathrm{NO}+\mathrm{NO}_{2}
$$

Nitrogen oxide gas, especially $\mathrm{NO}_{2}$ is easily to dissolve in water; this can accelerate the delivery of oxygen to liquid phase and speed up the reaction. The starting quantity of nitrogen oxide determines the $\mathrm{O}_{2}$ delivery speed from gas phase to liquid phase.

Under the conditions of reaction temperature $50{ }^{\circ} \mathrm{C}, \mathrm{M}$ : solvent $=1: 5$, under the different ratios of $\mathrm{O}_{2}$ to $\mathrm{NO}, \mathrm{k}=$ $\mathrm{O}_{2} / \mathrm{NO}$, observe the influence of oxygen partial pressure on complete oxidizing time of M (Fig. 4). 


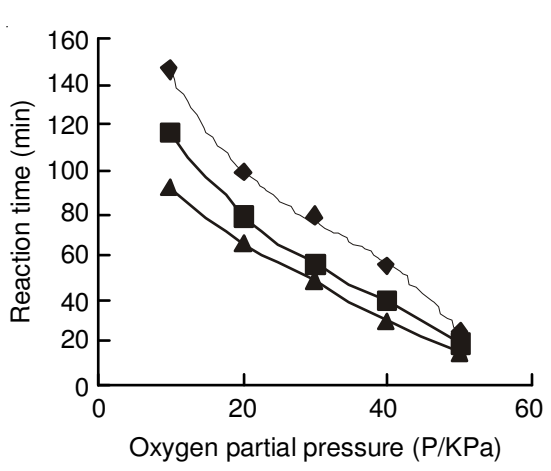

Fig. 4. Effect of different ratios of $\mathrm{O}_{2}$ to $\mathrm{NO}$ on reaction time

As nitric oxide gas can be rapidly oxidized to nitrogen dioxide in gas phase, nitrogen dioxide is easily to dissolve in liquid phase. Actually, nitric oxide gas can carry oxygen and make a fast transfer between gas-liquid bi-phase.

It can be concluded from Fig. 4, with the increasing use of nitric oxide gas ( $\mathrm{k}$ value decrease), the reaction speeds up, the time to complete reaction shortens. However, with the reduction of chemical reaction time, the particle size of product crystals became smaller. Especially when the oxygen partial pressure exceeds $50 \mathrm{kPa}$, the crystal grain size was so small that the filtration operation is difficult and even affects product quality.

With the extension of the reaction time, nitrogen oxide gas was gradually consumed in liquid phase, which made the mother liquor showing acidic.

Dissolution effect of chemical solvent and the judgment of the end-point: In previous reaction systems of producing DM, there exist gas phase, liquid phase, solid phases of $\mathrm{M}$ and DM. Since the properties of $\mathrm{M}$ and DM are similar. In DM crystals, always contains part of M, which decreases DM melting point and reduces the utilization of subsequent synthesis. The dissolution effect of water/ROH towards $\mathrm{M}$ reduces phase number of reaction system, the quantity of $\mathrm{M}$ that entrained by DM crystallization, thereby improves the crystalline quality of DM and ensures the purity of product. It also shortens the mass transfer process, accelerates the chemical reaction.

In the oxidation process, $\mathrm{M}$ is soluble and remained in liquid phase, only the product DM in insoluble and precipitated from the liquid phase, so the end point of the reaction is easy to judge, if the concentration of $\mathrm{M}$ in liquid phase does not change, the reaction reaches to the end. This offers a simple method to end the reaction in time.

After optimization of the oxidation reaction, there were ca. $0.2 \% \mathrm{M}$ still left in the mother liquid, even prolonged the reaction time to 5 times the remained $\mathrm{M}$ did not decrease. However, the solubility of DM was under $0.1 \%$ in water/ROH, this phenomenon indicated that, the $\mathrm{M}$ oxidation free radical reaction could not reach to the end. The remaining $M$ could only reclaim during the mother liquor-recovering period.

Reactor type for the oxidation reaction rate: Under the reaction conditions: temperature $50{ }^{\circ} \mathrm{C}$, oxygen partial pressure $40 \mathrm{KPa}$ and the usage of $\mathrm{NO}(\mathrm{k}=20)$, the concentration of $\mathrm{M}$ in liquid phase changed with the time in stirred tank reactor and fluidized bed reactor (Fig. 5).

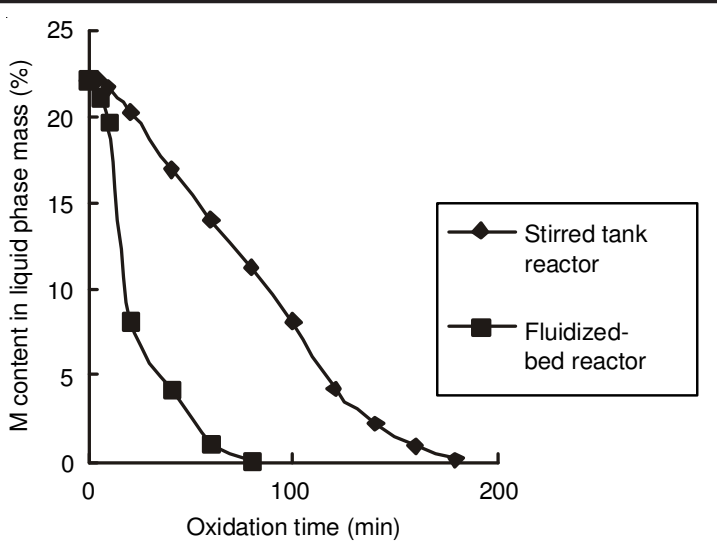

Fig. 5. Concentrations of $\mathrm{M}$ with the changing of reaction time in different reactors

Fig. 5 shows that, under the same reaction conditions, the concentration of $\mathrm{M}$ in fluidization reactor decrease faster than in stirred tank reactor. The fundamental difference of the two reactors is the fluidization reactor has a larger gas-liquid contact area than the stirred tank reactor. Therefore, when nitrogen oxide involves in this oxidation reaction, the reaction rate was under the control of the diffusion rate of oxygen, thus the product yield could increased proportionally when enlarged the gasliquid contact area, which offer the selections for chemical reactors and provide basis for design.

Effect of reactor types on crystal shape and quality of DM: Compared fluidized bed reactor with the stirred tank reactor, the former has a larger gas-liquid contact area. With the carrying of oxygen by nitric oxide gas, the mass transfer speeded up and accelerated the chemical reaction. Under fast reaction condition, the crystal shape and quality of DM was completely different with the one using ordinary stirred tank reactor.

The crystal shapes of DM that generated in common stirred tank reactor were rods or flake crystals and the colour were bright yellow. While the one generated in fluidized bed reactor was in whisker shape and the colour was pale yellow (Figs. 6 and 7). ${ }^{1} \mathrm{H}$ NMR $\left(\left(\mathrm{CD}_{3}\right)_{2} \mathrm{CO} 500 \mathrm{MHz}\right): \delta 7.44-7.48$ $(2 \mathrm{H}, \mathrm{t}, \mathrm{CH}), 7.54-7.58(2 \mathrm{H}, \mathrm{t}, \mathrm{CH}), 7.93-7.96(2 \mathrm{H}, \mathrm{d}, \mathrm{CH})$, 8.03-8.07 $(2 \mathrm{H}, \mathrm{d}, \mathrm{CH})$. The purity of the refined $\mathrm{M}$ is above $99 \%$. The spectra of ${ }^{1} \mathrm{H}$ NMR and HPLC are shown in supplementary material.

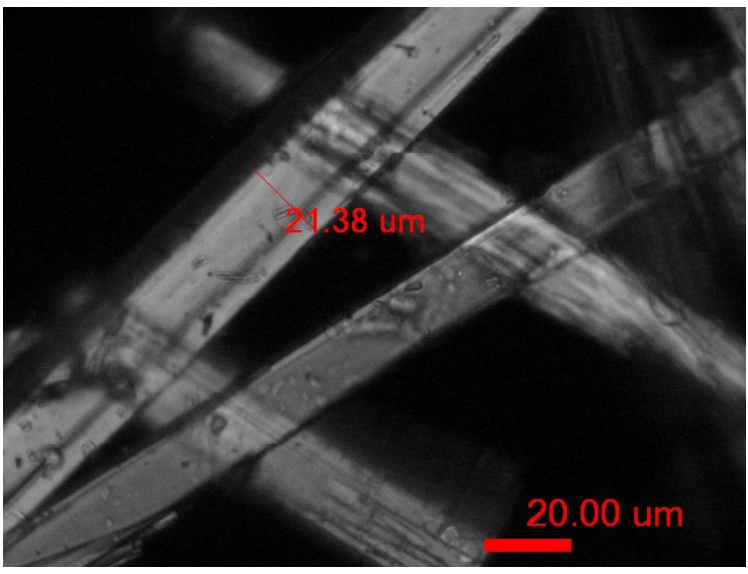

Fig. 6. Polarizing microscope photograph of DM crystals produced in fluidized bed reactor 


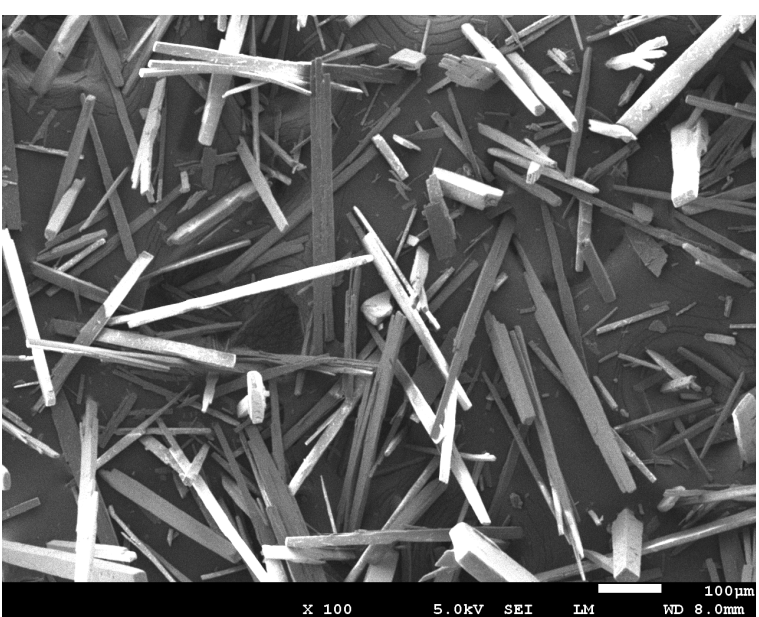

Fig. 7. SEM photo of DM crystals produced in fluidized bed reactor

Comparing the different DM that produced in different reactors, we found that the product that generated in fluidized bed reactor displayed close to colourless and after drying, it turned white. The product produced in stirred tank reactor contained $c a .98 .5 \%$ of DM, while the DM produced in fluidized bed reactor, the purity were usually above $99.0 \%$.

\section{Conclusion}

The water/ROH mixed solvent selected by using organic conception diagram have high solubility towards $\mathrm{M}$, which is beneficial to isolate and eliminate the poly-benzothiazole impurity and obtain high purity of $\mathrm{M}$ under recrystallization. During reaction process of oxidizing $\mathrm{M}$ to DM, in muti-phases of different components, water/ROH had a high solubility towards $\mathrm{M}$ and a low solubility towards DM. This made DM crystal consist the only solid phase in the system, which ensured the quality of DM essentially. The optimum conditions were: reaction temperature $50^{\circ} \mathrm{C}$, oxygen partial pressure 50 $\mathrm{KPa}$, nitrogen oxide gas carried oxygen from gas phase to liquid phase. The most suitable amount of nitrogen oxide was $1 / 25$ of $\mathrm{O}_{2}$, which could meet the needs for practical production. Compared with common stirred tank reactor, fluidized bed reactor enlarged the gas-liquid contact area and accelerated the reaction meanwhile it improved the crystal shapes of the products and increased the quality of DM dramatically.

\section{REFERENCES}

1. M.G.P. Page, Curr. Opin. Pharmacol., 5, 480 (2006).

2. B. Guignard, J.M. Entenza and P. Moreillon, Curr. Opin. Pharmacol., 5, 479 (2005).

3. J. Carlet, Clin. Microbiol. Infect., 5, 35 (1999).

4. J.F. Geiser and R.J. Hopper, Preparation of 2.2'-Dithiobis (benzothiazole) in an Aqueous/Alcohol Reaction Medium, US Patent 4755607, July, 5 (1988).

5. J.H. Kaplan and R.C. Kinstler, Continuous Process for Preparing Benzothiazyl Disulfide, US Patent 4482720, Nov 16 (1984).

6. W. Alfredo, Process for the Production of 2,2'-Dibenzothiazolyl disulphide, US Patent 4591647, May 27 (1986).

7. G. Danuta, S. Jerzy, W. Jerzy and B. Danuta, Process for the Preparation of 2,2'-Benzothiazolyl Disulfide, EP 0392052 A1, Oct 17 (1990).

8. O.A. Ermakov, G.F. Davydova, V.N. Shtyrkov and N.V. Grigorevia, J. Appl. Chem. USSR, 2, 349 (1977).

9. A.B. Kilimnik and E.S. Bakunin, Synthesis of Organic Disulfides, Transactions TSTU, 4, pp. 1007-1021 (2011).

10. J.J. Tazuma, Method of Preparation Dibenzothiazolyl Disulfides, US Patent 4463178, July 31 (1984).

11. E.L. Graeber and M.J. Lindstrom, Process for the Preparation of 2,2'Dithiobis(benzothiazole), US Patent 4859778, Aug 22 (1989).

12. H.G. Zengel, M. Bergfeld and L. Eisenhuth, Process for the Preparation of Dithiazolyl Disulfides, US Patent 4558135, Dec. 10 (1985).

13. W. Nolte, H. Konigshofen and A. Sicheneder, Process for the Preparation of Dithiazolyl Disulfide, US Patent 6124467, Sep 26 (2000).

14. S.T.A. Shah, K.M. Khan, M. Fecker and W. Voelter, Tetrahedron Lett., 44, 6789 (2003).

15. J. Zhai, The Research on Purification Technology of Refined DM, Chinese Polymer \& Additives, 2, pp. 38-39 (2004) (in Chinese).

16. X. Pan, Y. Wu, H. Zhang and X. Li, The Synthesis of Vulcanizing Accelerator DM, Chemical Propellants \& Polymeric Materials, 4, pp. 38-40 (1998) (in Chinese).

17. N. Li and X. Meng, Chin. J. Spectros. Lab., 1, 85 (2003) (in Chinese). 